ABDI: Jurnal Pengabdian dan Pemberdayaan Masyarakat ISSN: 2656-369X (Print), 2684-8570 (Online)

Volume 1 No. 2, Desember 2019

http://abdi.ppj.unp.ac.id/index.php/abdi

Email: abdi@ppj.unp.ac.id

DOI: https://doi.org/10.24036/abdi.vli2.8

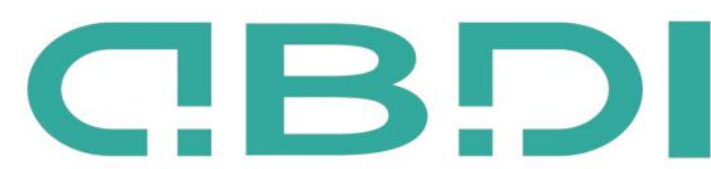

ABDI: JURNAL PENGABDIAN DAN PEMBERDAYAAN MASYARAKAT

\title{
Inovasi Olahan Kacang Tanah Dan Cabe Sebagai Oleh-Oleh Khas Daerah Objek Wisata Sungai Janiah
}

\author{
Anni Faridah ${ }^{1}$, Heru Pramudia ${ }^{2}$, Yofita Sandra ${ }^{3}$ \\ ${ }^{1}$ Jurusan Ilmu Kesejahteraan Keluarga Universitas Negeri Padang \\ ${ }^{2}$ Jurusan Pariwisata Universitas Negeri Padang \\ ${ }^{3}$ Pendidikan Seni Rupa Universitas Negeri Padang
}

E-mail: faridah.anni@gmail.com, pramudia.heru@gmail.com, yofita.sandra@yahoo.com

\begin{abstract}
Abstrak
Daerah wisata Ikan Sakti Sungai Janiah Nagari Tabek Panjang, Kecamatan Baso belum memiliki makanan khas sebagai oleh-oleh atau untuk konsumsi sehari-hari. Padahal potensi bahan pangan lokal (kacang tanah dan cabe) sangat mendukung untuk pembuataan produk pangan tersebut. Kegiatan pengabdian masyarakat ini bertujuan untuk memberdayakan Usaha Kecil dan Menengah (UKM) kuliner di lingkungan objek wisata guna ketersediaan pangan, baik sebagai oleh-oleh juga untuk konsumsi sehari-hari sehingga terjadi peningkatan perekonomian masyarakat daerah Sungai Janiah. Metode kegiatan yang dilakukan adalah penyuluhan, diskusi dan demonstrasi praktek langsung di lapangan. Peserta pelatihan mengikuti kegiatan pengabdian dengan antusias dan aktif. Peserta pelatihan mempraktekkan pembuatan produk olahan kacang dan olahan cabe. Kegiatan bersifat dua arah, sehingga peserta dapat melakukan diskusi jika ada permasalahan dalam melakukan kegiatan produksi. Luaran dari kegiatan ini adalah olahan berbahan kacang yang mencakup rakik, kipang kacang original, kipang kacang kulit buah naga, kipang kacang pandan, kipang empiang, serta olahan cabe yaitu sambal lado taraguak. Dari hasil kegiatan yang telah dilakukan dapat ditarik kesimpulan bahwa kegiatan pengabdian masyarakat meningkatkan pengetahuan, keterampilan dan pendapatan peserta pelatihan tentang inovasi dan variasi pengolahan produk olahan berbasis kacang tanah dan olahan cabe

Kata kunci: Cabe, Inovasi, Kacang Tanah, Oleh-oleh khas daerah

\section{Abstract}

The tourism area of Ikan Sakti Sungai Janiah Nagari Tabek Panjang, Baso District does not yet have special food for souvenirs or daily consumption. Though the potential of local food ingredients (peanuts and chili) is very supportive of the production of these food products. This community service activity is intended to empower Usaha Kecil dan Menengah (UKM) - small and medium businesses- culinary in the tourist attraction environment to utilize good food souvenirs, as well as for daily consumption to increase community improvement in Sungai Janiah. The method of activities undertaken is outreach, discussion, and demonstration of hands-on practice in the field. Trainees participate in service activities enthusiastically and actively. The participants practiced making processed beans and chilli processed products. This activity urges two directions, so participants can discuss if there are difficulties in conducting production activities. The output of this activity are products processed from peanuts containing rakik, kipang kacang, kipang kacang from dragon fruit shells, pandanus kipang kacang, kipang empiang, and chilli preparations, namely sambal lado taraguak. From the results of the activities carried out, conclusions can be drawn about community service activities that increase the knowledge, skills and funds of training participants about innovation and variations in the processing of processed products made from peanuts and chili.
\end{abstract}

Keyword: Chili, Inovation, Peanuts, Regional souvenirs

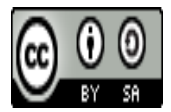

Received: 23 Agustus 2019 


\section{Pendahuluan}

Aktivitas pariwisata merupakan salah satu sektor pembangunan yang berkontribusi bagi pendapatan daerah. Pariwisata merupakan sebuah fenomena dan keterkaitan yang muncul karena interaksi wisatawan, bisnis penyedia jasa, pemerintah dan komunitas setempat dalam proses mendatangkan wisatawan atau pengunjung (Wardiyanta 2006). Pariwisata berkembang menjadi sektor yang memberikan efek nilai manfaat kepada banyak pihak dari pemerintah, masyarakat, ataupun swasta.

Pariwisata sebagai bagian dari industri kecil memiliki hubungan yang erat dikaitkan dengan ketersediaan makanan dan minuman (kuliner) di daerah wisata tersebut. Ketersediaan makanan dan minuman disuatu tempat wisata sangat penting bagi semuanya, baik wisatawan, penduduk setempat, dunia usaha, dan pemerintah. Dengan kata lain, pengembangan pariwisata berbasis potensi wisata mendukung pengembangan ekonomi lokal wilayah karena pemangku kepentingan yang terlibat yaitu pemerintah, dunia usaha, masyarakat lokal, dan organisasi masyarakat madani dalam suatu proses yang partisipatif.

Pemahaman pariwisata berbasis masyarakat sangat erat hubungannya jika dikaitkan dengan Pengembangan Ekonomi Lokal (PEL) karena tidak hanya membahas pariwisata sebagai unsur sektoral tetapi juga membahas pemberdayaan, dimana pemberdayaan semua pemangku kepentingan yang terlibat terutama masyarakat. Hal ini sesuai dengan definisi dan cakupan PEL. Menurut Munir (2007) PEL adalah suatu proses yang mencoba merumuskan kelembagaan-kelembagaan pembangunan di daerah, peningkatan kemampuan SDM untuk menciptakan produk-produk yang lebih baik serta pembinaan industri dan kegiatan usaha pada skala lokal.

Peningkatan kemampuan Sumber Daya Manusia (SDM) dan pembinaan industri atau usaha makanan di Sungai Janiah belum tersentuh baik oleh pemerintah ataupun masyarakat intelektual. Hal ini terlihat dari peninjauan tim dan wawancara dengan mitra Usaha Kecil dan Menengah (UKM) kuliner yang ada di objek wisata Ikan Sakti Sungai Janiah. Daerah ini potensial untuk mengolah pangan berbahan lokal seperti berbahan kacang tanah dan cabe yang produksinya banyak di daerah tersebut. Daerah objek wisata Ikan Sakti Sungai Janiah tergolong daerah subur dan daerah pertanian. Masyarakat menjual hasil panennya dalam kondisi mentah/belum diolah. Jika dijual dalam bentuk diolah, saat ini berupa pengolahan yang sangat tradisional yaitu kipang kacang, kipang ampiang, rakik dan belum ada olahan cabe. Jika musim panen, cabe memiliki harga jual yang murah ditingkat petani. Alangkah baiknya jika saat musim panen atau harga panen rendah, masyarakat setempat dapat mengolah bahan pangan lokal menjadi makanan yang disukai, menarik, enak, aman dan tahan lama serta menjadi oleholeh khas daerah tersebut.

Hasil observasi lansung ke objek wisata, terlihat kondisi penjual makanan dan minuman di daerah sekitar kolam ikan Sungai Janiah, antara lain terdapat 6 (enam) kios/meja milik masyarakat yang berjualan persis disekitar kolam Ikan Sakti Sungai Janiah. Jualan yang ditawarkan hanya berupa makanan olahan pabrik atau makanan instan dan kerupuk kuah. Selain adanya potensi objek wisata untuk dikembangkan, namun masih terdapat permasalahan yang dialami mitra, antara lain:

a. Masih rendahnya pengetahuan/wawasan mitra tentang penerapan inovasi produk olahan kacang serta olahan cabe.

b. Belum terampilnya mitra melakukan penerapan inovasi olahan kipang kacang, cabe dan juga rendahnya wawasan mitra tentang pengemasan hingga siap untuk dipasarkan

c. Produk olahan yang dihasilkan oleh unit pengolahan skala kecil masih jauh dari ketentuan sistem mutu nasional (higiene dan sanitasi; penggunaan bahan tambahan pangan; keamanan pangan termasuk halal).

Kegiatan pengabdian ini dilakukan dengan tujuan untuk memberdayakan UKM kuliner di lingkungan objek wisata Ikan Sakti Sungai Janiah guna ketersediaan pangan baik sebagai oleh-oleh, juga untuk konsumsi sehari-hari sehingga terjadi peningkatan perekonomian masyarakat setempat. Dilihat dari potensi yang dimiliki Jorong Sungai Janiah Nagari Tabek Panjang, dapat dilakukan peningkatan wawasan, pelatihan penerapan inovasi olahan kacang tanah dan cabe serta cara memasarkannya. 


\section{Metode Pelaksanaan}

Sasaran penyuluhan dan pelatihan inovasi dan variasi produk olahan berbasis kacang tanah dan olahan cabe ini adalah kelompok ibu-ibu anggota UKM kuliner di daerah Sungai Janiah yang berjumlah 19 orang. Metode kegiatan yang akan dilakukan untuk tercapainya tujuan pengabdian kepada masyarakat ini adalah metode ceramah, diskusi dan demonstrasi praktik langsung di lapangan yang didasari oleh evaluasi awal sebagai landasan untuk menentukan posisi pengetahuan kelompok sasaran mengenai inovasi dan variasi produk olahan berbasis kacang tanah dan olahan cabe.

\section{Hasil dan Pembahasan}

Beberapa tahapan kegiatan telah dilaksanakan, mulai dari tinjauan lokasi, penyuluhan hingga pelatihan penerapan inovasi dan variasi produk olahan berbasis kacang tanah dan olahan cabe. Berikut dijabarkan hasil dan pembahasan kegiatan pengabdian masyarakat satu persatu.

\section{Tinjauan Lokasi Pengabdian}

Kegiatan pengabdian diawali dengan meninjau lokasi kegiatan pengabdian masyarakat pada bulan Mei 2019, yaitu lingkungan Objek Wisata Ikan Sakti Sungai Janiah Nagari Tabek Panjang jorong Sungai Janiah, Kecamatan Baso. Hasil wawancara dengan wali nagari dan ketua mitra usaha UKM kuliner menyatakan bahwa usaha makanan baru sebatas memproduksi kipang kacang yang memiliki kemasan sangat sederhana (daun pisang kering yang kurang rapi) dan kurang variasi, penampilan tidak menarik, dan belum mengolah bahan pangan lokal karena ketidak tahuan bahwa cabe dapat diolah dan bisa tahan lama. Cabe hanya dikonsumsi rumah tangga dan dijual ke pasar-pasar tradisional saja, padahal daerah ini memiliki sambal lado Tarubuak yang layak dan potensial menjadi oleh-oleh khas daerah ini. Pengolahan berbagai macam makanan khas juga belum memperhatikan higiene, penyajian, penampilan dan keamanan pangan. Dengan demikian dapat dikatakan bahwa belum tersedia makanan khas yang berdaya saing sebagai oleh-oleh atau dikonsumsi sehari-hari

\section{Sosialisasi atau Forum Group Discussion (FGD)}

Setelah dilakukan peninjauan, selanjutnya dilaksanakan sosialisasi dengan memberikan informasi kepada masyarakat setempat bahwa akan diadakan pelatihan mengenai pengolahan kacang tanah dan cabe, sebagai oleh-oleh khas daerah. Sosialisasi dilaksanakan pada tanggal 1 Juli 2019 di Sungai Janiah. Pada kesempatan ini, peserta terlihat antusias dengan program yang akan dijalankan di daerah mereka.
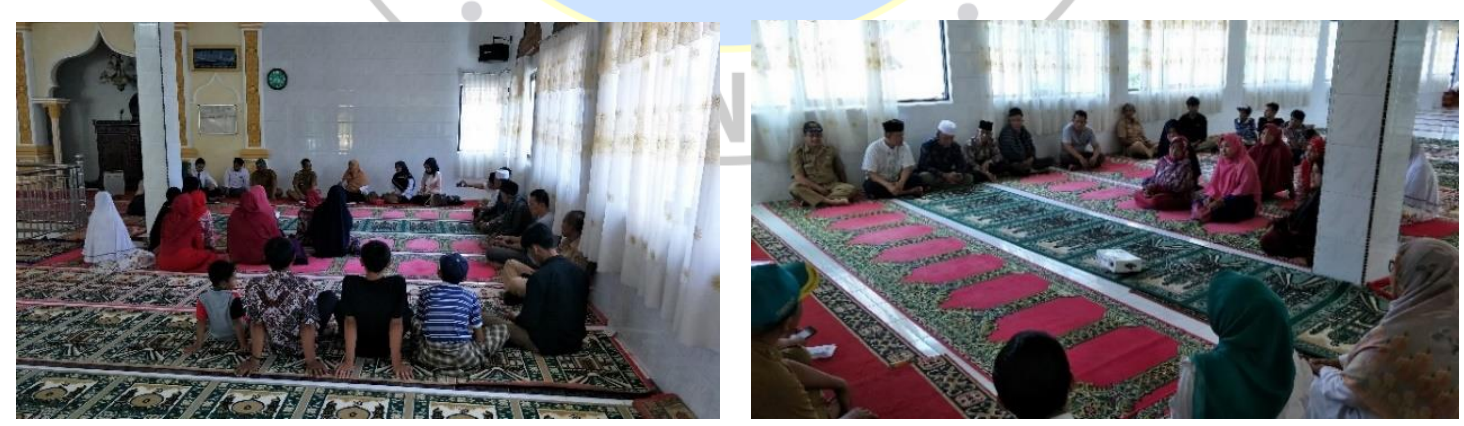

\section{Gambar 1. Sosialisasi atau Forum Group Discussion (FGD)}

Masyarakat Sungai Janiah menyambut baik kegiatan Pengabdian kepada Masyarakat yang dilakukan oleh tim dosen dari Universitas Negeri Padang ini. Masyarakat tertarik dan berminat untuk ikut serta dalam pelaksanaan kegiatan pelatihan penerapan inovasi olahan kacang tanah dan cabe sebagai oleh-oleh khas daerah. Pada tahap sosialisasi ini juga dilakukan diskusi dua arah dengan masyarakat mengenai penyuluhan dan pelatihan yang akan dilaksanakan, sehingga masyarakat dapat bertanya langsung dan berdiskusi kepada narasumber. Selain itu juga masyarakat memberi informasi 
tentang potensi bahan pangan local sungai Janiah yang lain, misalnya ubi jalar, buah naga, pisang dan singkong. Masyarakat berharap untuk berikutnya dilakukan olahan ubi jalar yang inovatif

\section{Penyuluhan Materi Higiene dan Sanitasi, Bahan Tambahan Pangan dan Keamanan Pangan}

Setelah dilakukan sosialisasi, kegiatan selanjutnya yang dilakukan adalah penyuluhan materi higiene dan sanitasi, bahan tambahan pangan dan keamanan pangan. Kegiatan ini dilaksanakan pada bulan bulan Juli 2019 di Sungai Janiah dan dihadiri oleh ibu-ibu kelompok anggota UKM kuliner di daerah setempat yang berjumlah 19 orang.

Materi penyuluhan pertama yang diberikan yaitu higiene dan sanitasi. Penerapan higiene dan sanitasi sangat penting dalam pengolahan makanan. Pada penyuluhan diberikan penjelasan tentang prinsip-prinsip higiene dan sanitasi makanan, yang mencakup pemilihan bahan makanan, penyimpanan bahan makanan, pengolahan makanan, pengangkutan makanan, penyimpanan makanan masak, dan penyajian makanan. Menurut Yulia (2016) higiene sanitasi makanan minuman yang baik perlu ditunjang oleh kondisi lingkungan dan sarana sanitasi yang baik pula, seperti kebersihan peralatan yang akan digunakan untuk mengolah makanan.

Selain higiene dan sanitasi makanan, personal higiene merupakan materi yang juga diberikan ketika penyuluhan. Menurut Rejeki (2015) personal higiene adalah upaya seseorang untuk memelihara derajat kesehatan dan kebersihan diri sendiri. Menjaga kebersihan dan kesehatan diri sendiri harus dilakukan untuk menghindari kontaminasi makanan yang dapat mengganggu kesehatan pelanggan, baik dari secara sehat fisik dan sehat psikologis

Materi penyuluhan yang kedua yaitu Bahan Tambahan Pangan (BTP). BTP adalah bahan atau campuran bahan yang secara alami bukan merupakan bagian dari bahan baku pangan, tetapi ditambahkan ke dalam pangan untuk mempengaruhi sifat atau bentuk bahan pangan. Produsen sangat perlu mengetahui BTP, karena masih banyak bahan kimia berbahaya yang digunakan produsen pangan dan memiliki efek berbahaya bagi kesehatan. Tujuan penambahan zat tambahan makanan adalah untuk meningkatkan atau mempertahankan nilai gizi dan kualitas daya simpan, membuat bahan pangan lebih mudah dihidangkan serta mempermudah dalam penyiapan bahan pangan (Julaeha, Nurhayati, and Mahmudatussa'adah 2016).

Selanjutnya diberikan materi penyuluhan terakhir, yaitu keamanan pangan. keamanan pangan adalah kondisi dan upaya yang diperlukan untuk mencegah Pangan dari kemungkinan cemaran biologis, kimia, dan benda lain yang dapat mengganggu, merugikan, dan membahayakan kesehatan manusia serta tidak bertentangan dengan agama, keyakinan, dan budaya masyarakat, sehingga aman untuk dikonsumsi. Wahyuni dan Sumarmi (2018) menjelaskan bahwa analisis risiko yang berkaitan dengan keamanan pangan dimulai dengan mengidentifikasi bahaya pangan.

Berdasarkan diskusi yang telah dilakukan antara narasumber dengan peserta, diketahui bahwa hal-hal yang berkaitan dengan higiene dan sanitasi, Bahan Tambahan Pangan (BTP), dan keamanan pangan belum sepenuhnya dipahami oleh masyarakat. Antusiasme peserta pelatihan akan materi yang diberikan terlihat jelas sebagaimana ditunjukkan pada Gambar 2.
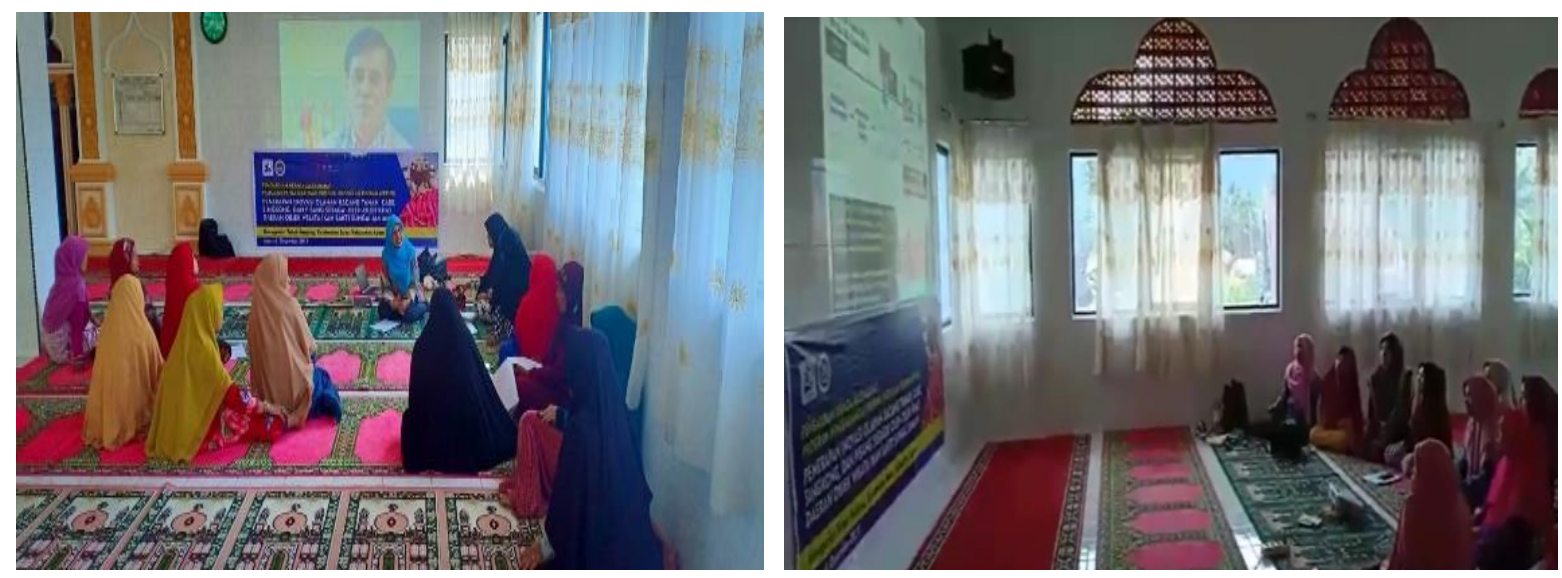

Gambar 2. Penyuluhan Materi Higiene dan Sanitasi, Bahan Tambahan Pangan dan Keamanan Pangan 


\section{Pelatihan Penerapan Inovasi dan Variasi Produk Olahan Berbasis Kacang Tanah dan Olahan Cabe}

Pada tahap ini, kegiatan diisi dengan demonstrasi oleh instruktur dan diikuti oleh perserta pelatihan. Adapun produk yang diolah yaitu olahan berbahan kacang yang mencakup rakik, kipang kacang original, kipang kacang kulit buah naga, kipang kacang pandan, kipang empiang, serta olahan cabe yaitu sambal lado taraguak. Peserta pelatihan diberikan pengetahuan tentang inovasi pewarna alami dari buah naga yang merupakan hasil panen masyarakat sekitar. Buah naga dapat memberikan warna merah pada makanan, sehingga dapat digunakan sebagai bahan pewarna. Bahan alami lain yang dapat dijadikan pewarna yaitu daun pandan yang dapat memberikan warna hijau pada makanan.

Peserta pelatihan juga diberikan pengetahuan tentang penerapan higien dan sanitasi yang sebelumnya sudah diberikan ketika penyuluhan. Seperti harus memakai apron atau celemek selama pengolahan makanan agar baju tetap bersih. Lalu harus menutup kepala agar rambut tidak jatuh ke makanan, sehingga makanan tidak terkontaminasi. Higien dan sanitasi ini merupakan komponen penting yang perlu diperhatikan dalam peningkatan keamanan pangan. Teknik pengolahan produk olahan kacang tanah dan olahan cabe yang sesuai standar pengolahan juga baru diketahui oleh peserta.

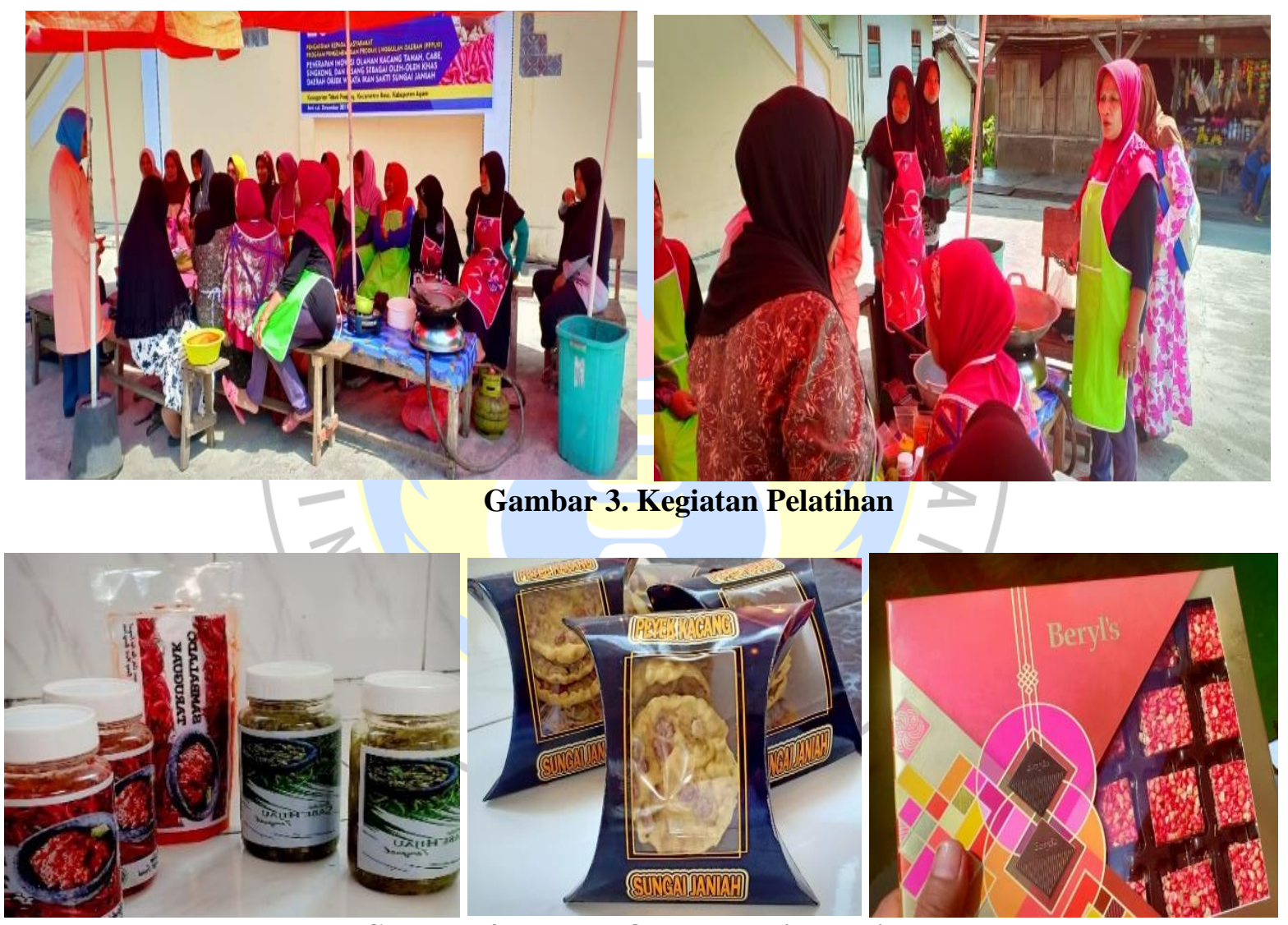

Gambar 4. Produk Olahan Hasil Pelatihan

Penyuluhan Materi Manajemen, Pemasaran, dan Izin Industri Rumah Tangga Pangan (IRT-P)

Kegiatan ini diisi dengan penyuluhan materi tentang manajemen pemasaran dan pengurusan izin Pangan Industri Rumah Tangga Pangan (P-IRT). Materi pertama yang diberikan yaitu manajemen pemasaran. Kemasan dan label merupakan kunci penting yang harus diperhatikan dalam pemasaran produk. Menurut (Indraswati 2017) kemasan adalah tempat untuk menempatkan produk yang dapat berupa wadah. Kemasan berfungsi untuk melindungi produk sehingga lebih awet, memudahkan penyimpanan, distribusi, pemakaian, promosi dan juga memberikan jaminan kepastian pada konsumen serta berwawasan lingkungan. Kemasan yang biasa digunakan yaitu berbahan plastik, mika, kertas/karton, botol. 
Label pangan adalah keterangan yang mendeskripsikan pangan, dapat berbentuk gambar, tulisan, kombinasi keduanya, atau bentuk lain yang disertakan pada pangan. Label dapat dimasukkan kedalam kemasan atau ditempelkan atau merupakan bagian dari kemasan pangan berdasarkan Undang-Undang Nomor 18 tahun 2012 tentang Pangan. Label pada umumnya berisi informasi berupa nama atau merek produk, bahan baku, bahan tambahan komposisi, informasi gizi, tanggal kadaluarsa, isi produk, dan keterangan legalitas.

Penyuluhan ini berguna agar produk pangan olahan masyarakat mempunyai kemasan dan label yang informatif, aman dan menarik. Setelah kegiatan penyuluhan ini, diharapkan peserta mampu menerapkan manajemen usaha yang baik dengan membentuk suatu wadah untuk memasarkan produk di suatu lokasi yang strategis dan representatif. Serta mampu mengaplikasikan pengemasan dan penyimpanan yang baik terhadap produk-produk yang telah dihasilkan.

Selanjutnya diberikan materi tentang izin Pangan Industri Rumah Tangga (P-IRT). Berdasarkan peraturan Badan Pengawas Obat dan Makanan nomor 22 tahun 2018 tentang Pedoman Pemberian Sertifikat Produksi Pangan Industri Rumah Tangga, Industri Rumah Tangga Pangan (IRTP) diartikan sebagai perusahaan pangan yang memiliki tempat usaha di tempat tinggal dengan peralatan pengolahan pangan manual hingga semi otomatis. Nomor P-IRT sangat penting peranannya dalam pangan produksi IRTP. Jika pangan produksi IRTP tidak memiliki nomor P-IRT, maka pangan yang diproduksi belum terjamin mutu dan keamanannya serta dapat mengancam kesehatan konsumen. Produk pangan yang tidak memenuhi ketentuan standar, persyaratan kesehatan, dan/atau membahayakan kesehatan dilarang untuk diedarkan, ditarik dari peredaran, dicabut izin edar dan disita untuk dimusnahkan sesuai dengan ketentuan perundang-undangan (Peraturan Kepala Badan Pengawas Obat dan Makanan Republik Indonesia Nomor HK.03.1.23.04.12.2206 Tahun 2012 Tentang Cara Produksi Pangan yang Baik untuk Industri Rumah Tangga)
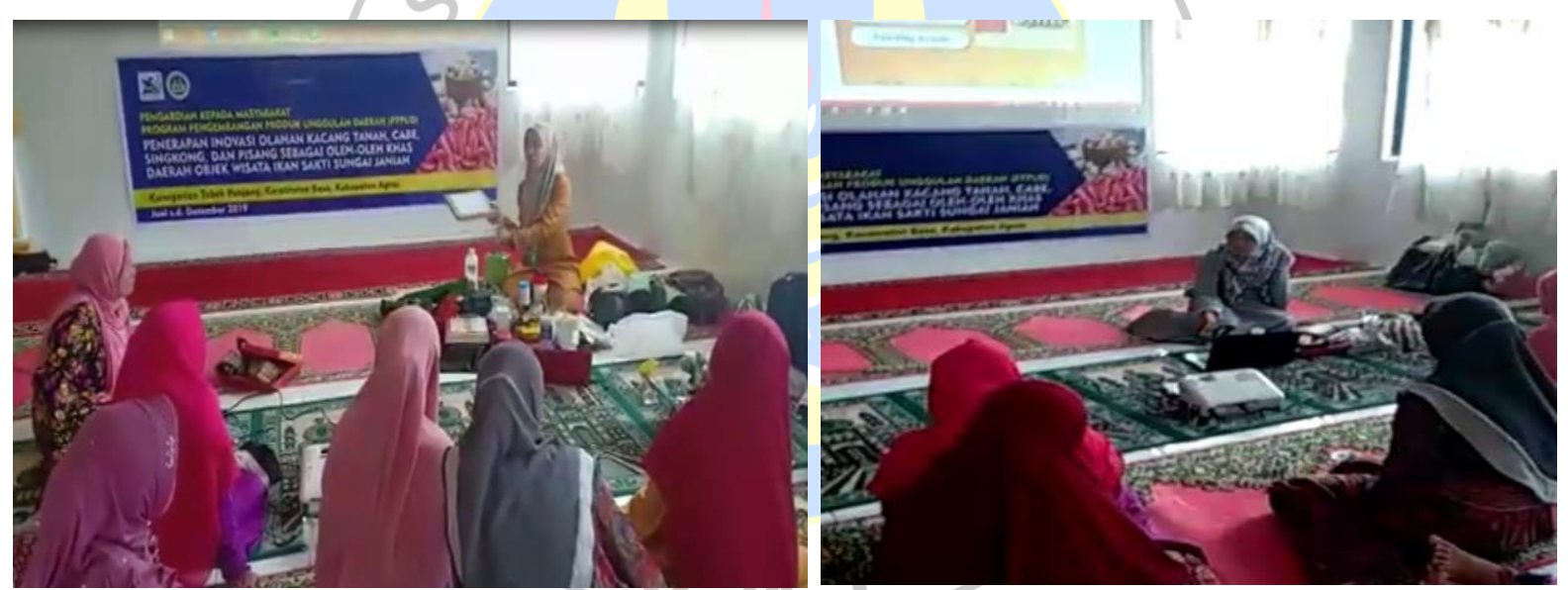

Gambar 5. Penyuluhan Materi Manajemen dan Pemasaran, dan Izin Pangan Industri Rumah Tangga

\section{Kesimpulan}

Kegiatan Pengabdian kepada Masyarakat di daerah Sungai Janiah dapat diterima dengan baik oleh masyarakat sekitar. Pelaksanaan kegiatan pengabdian kepada masyarakat dapat meningkatkan pengetahuan, dan keterampilan mengenai inovasi dan variasi produk olahan berbasis kacang tanah dan olahan cabe serta peningkatan pendapatan peserta. Produk olahan yang dihasilkan yaitu berbahan kacang yang mencakup rakik, kipang kacang original, kipang kacang kulit buah naga, kipang kacang pandan, serta olahan cabe yaitu sambal lado taraguak baik cabe hijau maupun cabe merah. Kegiatan pengabdian ini juga meningkatkan pengetahuan masyarakat mengenai higiene dan sanitasi, bahan tambahan pangan dan keamanan pangan, kemasan yang menarik dan tepat, manajemen dan pemasaran, serta izin Pangan Industri Rumah Tangga (P-IRT). Peserta pelatihan aktif dan dapat menerima materi dengan baik. 


\section{Daftar Pustaka}

Indraswati, Denok. (2017). Pengemasan Makanan. Ponorogo: Forum Ilmiah kesehatan (FORIKES).

Julaeha, Leha, Ai Nurhayati, dan Ai Mahmudatussa'adah. (2016). Penerapan Pengetahuan Bahan Tambahan Pangan Pada Pemilihan Makanan Jajanan Mahasiswa Pendidikan Tata Boga UPI. Media Pendidikan, Gizi Dan Kuliner 5 (1): 17-26.

Munir, Risfan. (2007). Pengembangan Ekonomi Lokal Partisipatif: Masalah, Kebijakan Dan Panduan Pelaksanaan Kegiatan. Jakarta: Local Governance Support Program (LGSP).

Rejeki, Sri. (2015). Sanitasi, Hygiene, Dan Kesehatan \& Keselamatan Kerja(K3). Bandung: Rekayasa Sains.

Wahyuni, Hana Catur, and Wiwik Sumarmi. (2018). "Pengukuran Risiko Keamanan Pangan Pada Sistem Rantai Pasok Ikan Segar." J@ti Undip: Jurnal Teknik Industri, 13 (1): 37. https://doi.org/10.14710/jati.13.1.37-44.

Wardiyanta. (2006). Metode Penelitian Pariwisata. Yogyakarta: ANDI.

Yulia. (2016). "Higiene Sanitasi Makanan, Minuman Dan Sarana Sanitasi Terhadap Angka Kuman Peralatan Makan Dan Minum Pada Kantin.” Jurnal Vokasi Kesehatan, 2 (1): 55-61.

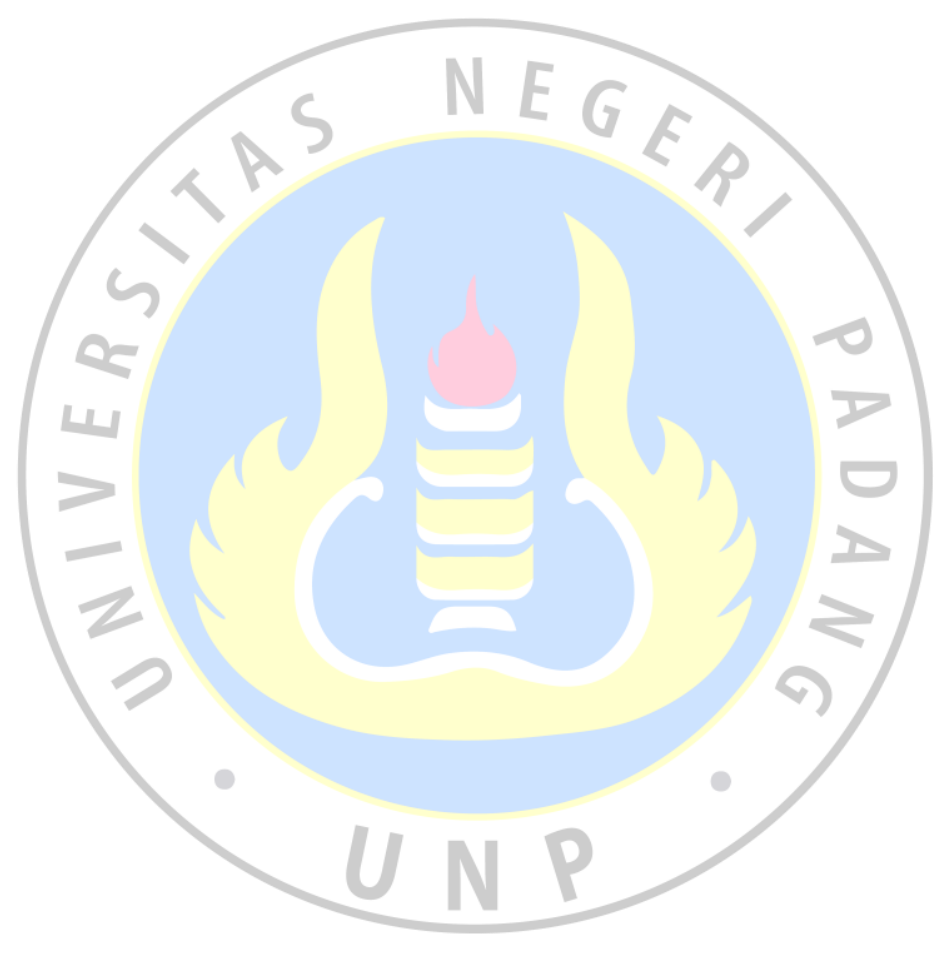

